\title{
Damage and Failure Mechanism of Bullets Impact Sapphire based on LS-DYNA
}

\author{
Siyu LIU, Zhipeng QU, Mingyun LV, Guangyuan MA \\ School of Aeronautic Science and Engineering \\ BUAA \\ Beijing, China \\ e-mail: liusiyutvs@163.com,15936503630@163.com, a80636398@163.com, GeorgeMar@163.com
}

\begin{abstract}
Based on the Johnson-Holmquist-Ceramics material model in LS-DYNA, the penetration process of the bullet impact sapphire plate is simulated by finite element method, and the penetration failure mechanism is also analyzed. Four main observations are obtained-First, when the bullet hits the sapphire plate, the warhead does not invade the panel immediately, but is firstly roughened and abraded. Secondly, the force on the warhead increased sharply and reached the peak value in the process of the formation of the sapphire smash cone. Thirdly, after the smash cone is completely formed, the plate strength decreases gradually and the force of the projectile appears fluctuating or decreasing. Finally, in the whole penetration process, the fragmentation and cracking of sapphire mainly serve to absorb most of the kinetic energy of the bullets and to reduce the bullet speed. This study provides a reference for the design of bulletproof composite armor.
\end{abstract}

Keywords-component; sapphire; bullet impact; penetration; LS-DYNA

\section{INTRODUCTION}

The Bullet proof transparent plates is a kind of transparent structure which can resist the impact of bullet and shrapnel, because of its protective transparency and capability, it is widely used in military, anti-terrorism, riot, civil aviation, finance, insurance and other fields. The most common transparent plates is bulletproof glass, Its bullet proof principle is that the glass transforms the impact kinetic energy of the bullet into the elastic potential energy of the glass and the surface energy after breaking[1]. Recently most materials of bulletproof glass are inorganic and organic. In certain areas, there are irreparable flaw in the material of bulletproof glass, such as when glass (even optical glass) under visible light transmittance is high, but in the light of infrared ratio was significantly reduced, and even become opaque.

Transparent sapphire material has the characteristics of high hardness high elastic modulus and high strength properties[2]. It can be used as a new type of reinforced material for bulletproof transparent parts[3]. It can also be manufactured into large size sheet by modular connection mode. After matched with the inorganic glass, PC plate and film, Transparent sapphire material bring obvious advantages in many aspects, especially in light weight and comprehensive protection performance. Saint Gobain group use edge growth techniques to create sapphire plate with a thickness of $10.9 \mathrm{~mm}$ and a size of $304.8 \mathrm{~mm} * 469.9 \mathrm{~mm}$ which is the largest sapphire flat plate production at present after polished. American materials system Corporation studied the process of joining $0.2 \sim 0.5 \mathrm{~mm}$ sapphire wafer as intermediate layer. The sapphire joint was heated to $1600 \sim 1750^{\circ} \mathrm{C}$ for $1 \sim 8$ hours under $2.6 \sim 10 \mathrm{MPa}$ pressure. The later study showed that the ceramic pieces at the junction were diffused to sapphire under high temperature, so the strength of the joint was almost the same as that of the sapphire. The United States has made great progress in sapphire connection technology, sapphire has been applied to F-35 and F-22 fighters, Cockpit of AH-64 Apache helicopter also uses sapphire composite transparent technology. Therefore, as a new type of bulletproof transparent material, sapphire gradually shows prominent application advantage and development prospects in many fields [4, 5].

The penetration process of bullet impact high performance bullet proof transparent parts is a very complicated and rapid mechanical process which involve many factors, such as bullets, target shape, size, dynamic properties of bullets, target material and constitutive equation, thermal properties, communication flow of material under high strain rate stress wave, the friction and fracture, crack initiation and propagation and so on. Through the study of anti-elastic transparent material under high rate deformation mechanism of polymer, the mechanism of interaction between anti elastic transparent and high-speed impact, we can better choose different properties of glass, glass ceramics and polymers as part of composite armor.

In order to study the mechanical process of impact damage of transparent composite projectile, the impact damage and failure mechanism of various materials should be studied firstly[6]. Tan Shengzhi, Yao Xiaohu and others used finite element method to calculate the response process of inorganic glass plate under rigid body impact and analyzed the mechanism of damage and failure[7]. The simulation result shows that the radial crack occurs first when the single layer inorganic glass plate is impacted, and then a circular crack is formed, and the inorganic glass plate is broken into fragments under the interlaced action of the radial crack and the circumferential crack. The occurrence of circumferential cracks absorbs a lot of energy of impact materials, which is the main reason for the decrease of bullet velocity. Therefore, the circumferential crack has a very important influence on the energy absorption effect of inorganic glass plates.

In this paper, the finite element model of projectile impacting sapphire plate is established by LS-DYNA software, and the response process of sapphire plate under 
the impact of typical bullets is calculated. The influence of the failure steps, thickness and impact velocity on the energy absorption efficiency of sapphire was analyzed.

\section{PENETRATION MODEL}

\section{A. Geometric Model Mesh Generation}

The impact model of sapphire plate and high speed impact material is shown in Figure 1. The actual size of PC board is $500 \mathrm{~mm} * 500 \mathrm{~mm} * 8 \mathrm{~mm}$. In order to improve the computational efficiency, considering the symmetry of the problem, the $1 / 4$ model of sapphire bullet model is established, so the model size of sapphire plate is $250 \mathrm{~mm} * 250 \mathrm{~mm} * 10 \mathrm{~mm}$. Because the size of the plate is far greater than the diameter of the bullet, in order to make the result more accurate and improve the computational efficiency, we use the variable density mesh grid in the region to divide the bullet very close, but in the field of bullet away from the grid, gradually become larger, as shown in Figure 2. The finite element model contains 75296 elements and 82995 nodes. In order to improve the computational efficiency, the single point integral hexahedron element is adopted. In this paper, the $12.7 \mathrm{~mm}$ penetrator core is chosen as the impact shell which impact speed is $488 \mathrm{~m} / \mathrm{s}$, and the geometric size and model parameters of the bullet are shown in Figure 3 and TABLE I respectively.

TABLE I. MODEL PARAMETERS OF ARMOUR PIERCING INCENDIARY BOMB

\begin{tabular}{|c|c|}
\hline Model parameter & sapphire \\
\hline density(kg/m3) & 7850 \\
\hline shear modulus(GPa) & 77 \\
\hline Complete normalized strength parameter & 1540 \\
\hline Complete fracture strength parameters & 510 \\
\hline Strength parameter & 1.03 \\
\hline Fracture strength parameter & 0.26 \\
\hline Complete strength parameter & 0.014 \\
\hline Reference strain rate EPSI & 1 \\
\hline The maximum tensile strength(MPa) & 293 \\
\hline Maximum normalized strength parameter & 0 \\
\hline Hugoniot elastic limit (MPa) & 1763 \\
\hline $\begin{array}{c}\text { The pressure exponent Hugoniot under the } \\
\text { elastic limit of Phel (MPa) }\end{array}$ & 293 \\
\hline $\begin{array}{c}\text { A small portion of the elastic energy loss is } \\
\text { converted to the static energy }\end{array}$ & 1 \\
\hline From plastic strain to fracture parameter & 0.7 \\
\hline From plastic strain to fracture index & 1 \\
\hline Bulk modulus(GPa) & 1.33 \\
\hline Equation of state parameter (GPa) & 0 \\
\hline Equation of state parameter (GPa) & 0 \\
\hline Failure criteria & 0.46 \\
\hline
\end{tabular}

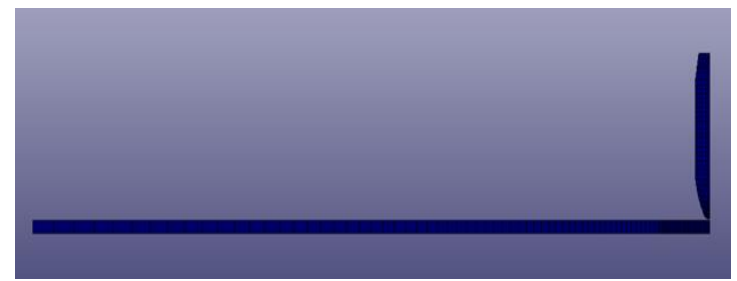

Figure 1. Calculation model of projectile target.

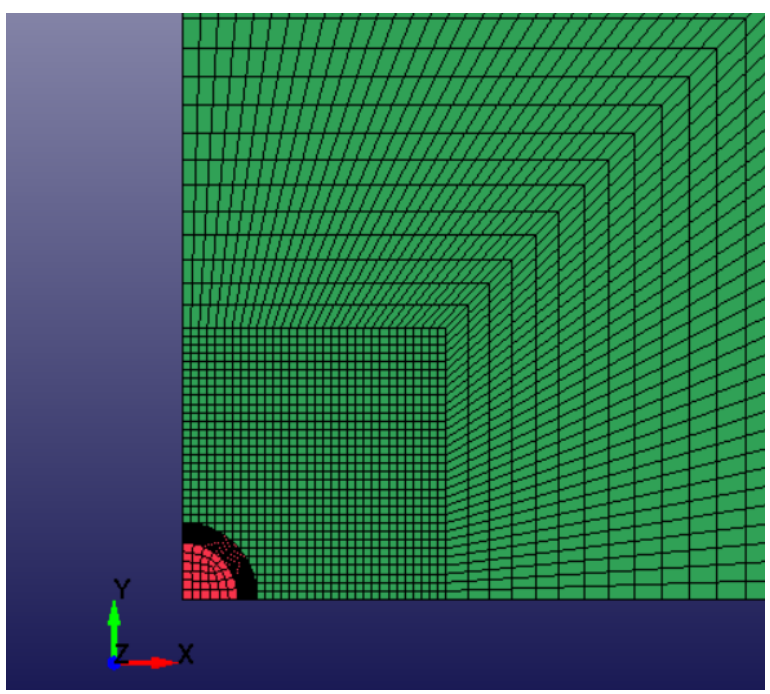

Figure 2. Sapphire plate mesh generation.

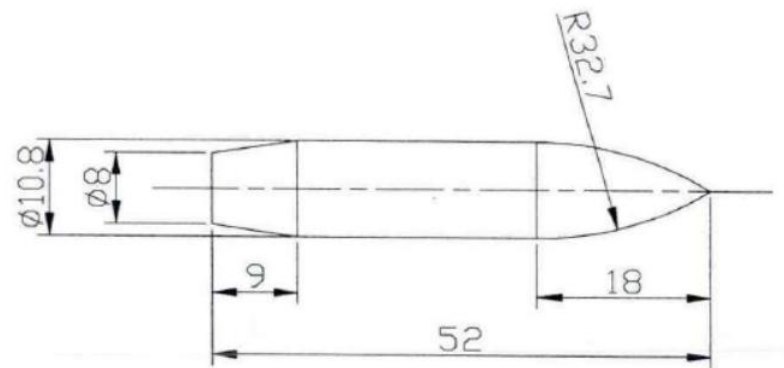

Figure 3. Geometric dimension of $12.7 \mathrm{~mm}$ penetrator core.

\section{B. Contact Control and Boundary Conditions}

Considering the penetration between the bullet and the sapphire, the surface erosion contact between the bullet and the sapphire plate is adopted. To achieve the destruction of the material through the failure of the control unit, and the material constitutive equation of damage parameters and failure to control the plastic strain, when the parameter reaches the threshold, unit material failure appears, LSDYNA will automatically delete the corresponding node and unit. Because a single point integral is used, the hourglass must be controlled to avoid the zero energetic mode.

Because the 1/4 model is established, symmetric boundary conditions must be applied. The symmetric boundary conditions for $\mathrm{X}$ are applied on the plane of $\mathrm{x}=0$, and the symmetric boundary conditions for $y$ are applied on 
the plane of $y=0$. Because the plate is fixed around it, the freedom of the nodes around the plate should be restrained.

\section{Material Model and Parameters}

In this paper, the JH2 model is used in sapphire, which has the advantage of accurately describing the damage and damage behavior of materials, and the calculation efficiency is high. In 1994, Johnson and Holmquist modified and perfected the JH-1 constitutive model describing the dynamic loading of brittle materials, and put forward the $\mathrm{JH}$ 2 model.

The JH-2 model[8] is composed of strength model, damage accumulation failure model and pressure specific volume relationship (including expansion effect) of three parts, through the description of the damage factor $\mathrm{D}$ without damage to the material and material damage strength. The material is evolved from the incomplete damage state through the cumulative failure model. Its main features are:

- Assume the injury is a process of accumulation, the material has a softening process.

- The strength and pressure are normalized by the effective strength and pressure components of the elastic limit of rain, respectively, which makes the constant of many materials dimensionless. It is convenient to use the program to debug the model parameters when the experimental data is insufficient.

- $\quad$ Strength and damage are the more perfect analytic functions of pressure and other variables.

The material parameters of the Johnson-HolmquistCeramics (JH2) model in LS-DYNA are shown in table 2[9].

TABLE II. PARAMETERS OF CONSTITUTIVE MODEL FOR SAPPHIRE JH-2

\begin{tabular}{|c|c|}
\hline Model parameter & sapphire \\
\hline density $(\mathrm{kg} / \mathrm{m} 3)$ & 3980 \\
\hline \multicolumn{2}{|l|}{ shear modulus $(\mathrm{GPa})$} \\
\hline Complete normalized strength parameter & 0.93 \\
\hline Complete fracture strength parameters & 0.31 \\
\hline Strength parameter & 0 \\
\hline Fracture strength parameter & 0.6 \\
\hline Complete strength parameter & 0.6 \\
\hline Reference strain rate EPSI & 1 \\
\hline The maximum tensile strength(MPa) & 400 \\
\hline Maximum normalized strength parameter & 0 \\
\hline \multicolumn{2}{|l|}{ Hugoniot elastic limit (MPa) } \\
\hline $\begin{array}{l}\text { The pressure exponent Hugoniot under the elastic } \\
\text { limit of Phel (MPa) }\end{array}$ & 1460 \\
\hline $\begin{array}{l}\text { A small portion of the elastic energy loss is } \\
\text { converted to the static energy }\end{array}$ & 1 \\
\hline From plastic strain to fracture parameter & 0.005 \\
\hline From plastic strain to fracture index & 1 \\
\hline Bulk modulus(GPa) & 228 \\
\hline Equation of state parameter $(\mathrm{GPa})$ & 0 \\
\hline Equation of state parameter $(\mathrm{GPa})$ & 0 \\
\hline Failure criteria & 1.6 \\
\hline
\end{tabular}

\section{CALCULATION RESULTS AND ANALYSIS}

\section{A. Penetration Process Analysis}

Figure 4 Figure 6 shows the evolution and formation of the cone in the first $30 \mu \mathrm{s}$ of the $12.7 \mathrm{~mm}$ projectile penetrating the sapphire target. The formation of the broken sapphire cone can be divided into two stages:

In the first stage $(\mathrm{t}<20 \mu \mathrm{s})$, there is a large compressive stress in the contact area of the projectile target. The damage of the material occurs and the damage zone appears on the sapphire plate.

The second stage $(\mathrm{t}=20 \mu \mathrm{s})$, the compressive stress wave arrives at the interface of the panel backplane, and the reflected stretching wave destroys the sapphire material in the contact area between the panel and the back panel. From the diagram, it can be clearly seen that the panel material at the interface of the panel is damaged. The reflection tensile stress wave propagates continuously from the back of the panel to the projectile direction, and the damage degree of the sapphire material increases along the propagation path of the wave. When $\mathrm{t}=30 \mu \mathrm{s}$, the damage zone is connected with the damage zone which is developed from the front panel to the inside of the panel, and the smash cone is formed. At the same time, the back of sapphire panel also produces radial damage and intensifies with the action time of projectile target. In the initial stage of the impact, the warhead failed to invade the sapphire panel, but was blunted and abraded.

In Figure 8 Figure 13 shows the process of penetration of a projectile into sapphire. It can be seen from the Figure 8 Figure 11 that the degree of smash cone of sapphire increases, the bullet invades the panel, and the extrusion and cone action of the projectile and the back plate and the backboard cause obvious deformation. Figure 12 shows the stress nephogram when the bullet is just going to penetrate the sapphire. Figure 13 shows the stress nephogram when the bullet penetrates the sapphire.

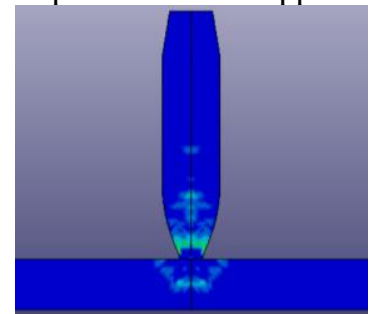

Figure 4. $\mathrm{t}=10 \mu \mathrm{s}$.

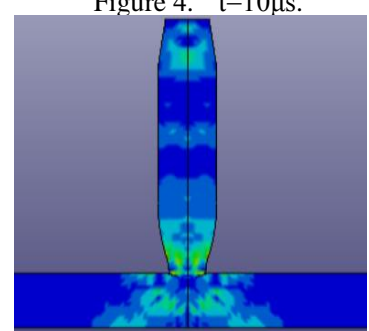

Figure $6 . \mathrm{t}=30 \mu \mathrm{s}$.
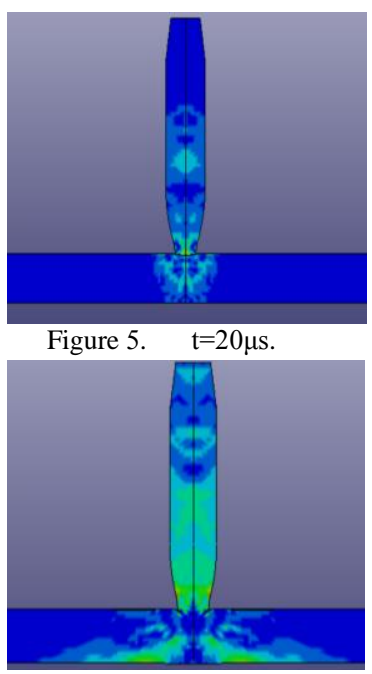

Figure 7. $\mathrm{t}=40 \mu \mathrm{s}$. 

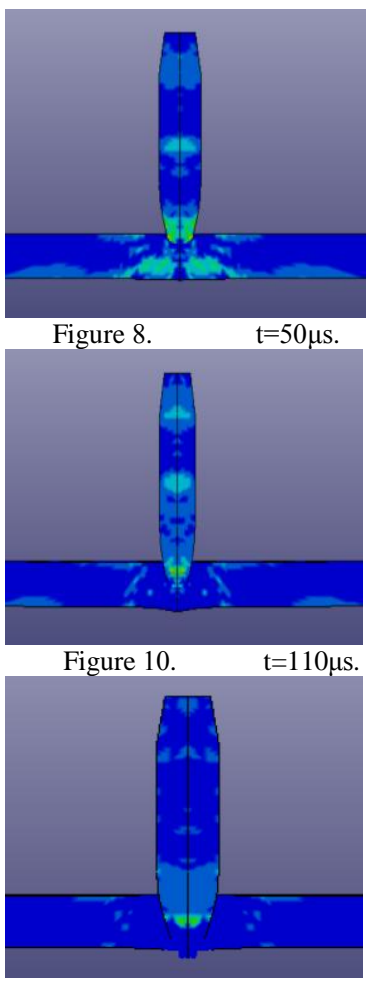

Figure 12.

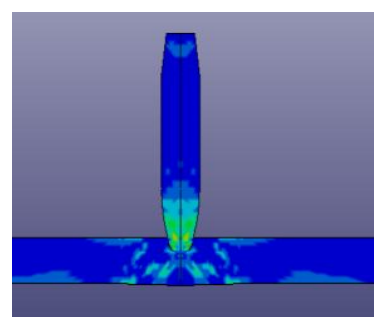

Figure $9 . \quad \mathrm{t}=60 \mu \mathrm{s}$.

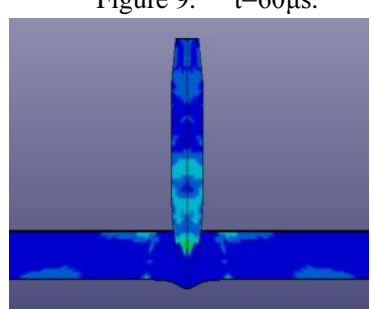

Figure 11. $\mathrm{t}=150 \mu \mathrm{s}$.

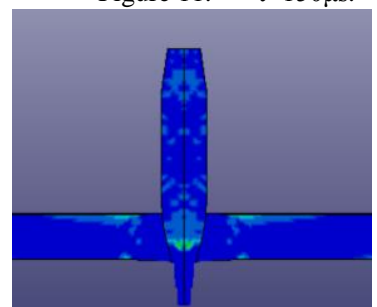

Figure 13. $\mathrm{t}=310 \mu \mathrm{s}$.

\section{B. Analysis of Bullet Motion Sate}

The acceleration curve of the bullet is shown in Figure 14. It can be seen from the figure that the acceleration time curve shows a single peak, which indicates that the sapphire has a strong barrier to the projectile in the penetration process. When $\mathrm{t}=$ tconnid (crushing cone formation time), warhead direction stress increased rapidly, and reached the peak. Sapphire panel has the highest strength in this period, and has a good bulletproof performance. When $t>t$ tconnid, the sapphire smash cone has been formed, the strength has been decreasing, and the force of the projectile has fluctuated or decreased. When $t>310 \mu \mathrm{s}$, the force of warhead is almost zero in each test, and the action process of projectile and sapphire panel is finished.

Figure 15 shows the kinetic energy curve of the bullet. It can be seen from the diagram that the curve is divided into two sections, the descending section and the platform section. In the first descent stage, the projectile and the panel acted on the sapphire. The strength of the sapphire material was higher, the abrasion of the missile body occurred, and the mass loss was greater. The velocity and kinetic energy of the core decreased greatly; In the platform stage, the projectile is still mainly and panel, but sapphire cone crusher crushing strength decreased, the kinetic energy of the bullet tended to be constant, the basic quality of the projectile the end of the penetration process unchanged, and the penetration process is finished.

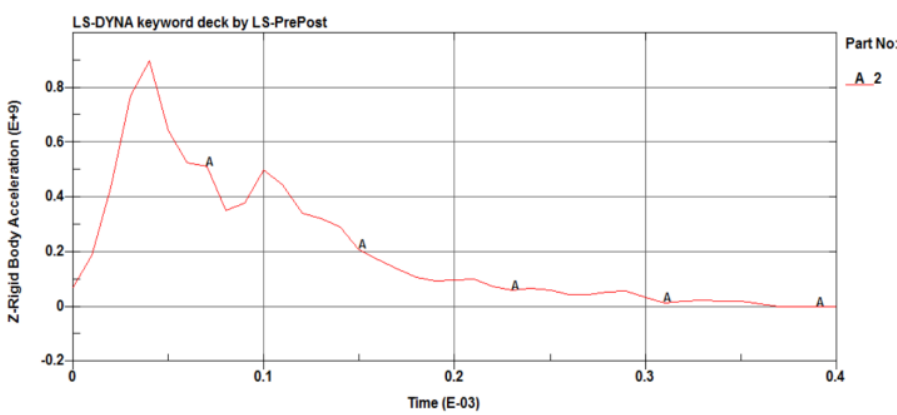

Figure 14. The acceleration curve of bullet

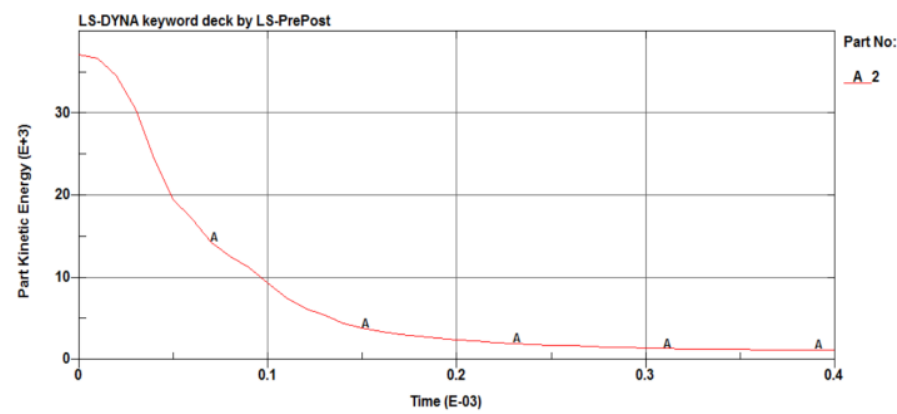

Figure 15. Kinetic energy curve of a bullet

\section{CONCLUSION}

The calculation results show that the warhead does not invade the panel immediately, but it firstly roughened and abraded. Under the interaction between the compressive stress wave and the panel, the sapphire plate forms the smash cone in the impacted region. With the penetration of bullets, the degree of smash cone increases. During the formation of smash cone, the projectile is seriously abraded, the mass loss is large, the kinetic energy drops sharply, and the acceleration also reaches the peak. The sapphire panel has the highest strength in the period of time, and plays a good bulletproof performance. After the smash cone is completely formed, the plate strength decreases gradually and the force of the projectile appears fluctuating or decreasing.

Therefore, in the design of composite armor, it is recommended to use sapphire as the front panel to absorb the kinetic energy of most of the bullets and reduce the speed of the bullets by breaking and cracking the sapphire[10]. The rear panel uses the ductile material to absorb the kinetic energy of the remaining bullets with elastic energy, and also prevents the target plate from splashing.

\section{REFERENCES}

[1] G. Qiu, "Study on the Structures and Materials of a New Bulletproof Composites Armor," Fiber Composites, 2005.

[2] V. A. Tatartchenko, Sapphire Crystal Growth and Applications: John Wiley \& Sons, Ltd, 2010

[3] K. Friedman, "Bulletproof glass safety system," ed, 2009.

[4] R. L. Gentilman, J. Askinazi, and J. W. Locher, "High-strength edgebonded sapphire windows," Proceedings of SPIE - The International Society for Optical Engineering, vol. 3705, pp. 282-287, 1999.

[5] R. L. Gentilman, D. Fiore, and J. Askinazi, "Large-area sapphire windows," Proc Spie, vol. 5078, pp. 54-60, 2003. 
[6] K. A. Dannemann, S. Chocron, A. E. Nicholls, and C. E. A. Jr, "Compressive damage development in confined borosilicate glass," Materials Science \& Engineering A, vol. 478, pp. 340-350, 2008.

[7] S. Z. Tan, X. H. Yao, S. G. Zang, P. Yu, L. H. Zhang, and Z. Q. Li, "Damage and failure mechanism of inorganic glass under impact by rigid projectile," Beijing Ligong Daxue Xuebao/transaction of Beijing Institute of Technology, vol. 34, pp. 18-20, 2014.
[8] D. S. Cronin, K. Bui, C. Kaufmann, G. Mcintosh, and T. Berstad, "Implementation and validation of the Johnson-Holmquist ceramic material model in LS-DYNA," European Ls, 2004.

[9] G. Mcintosh, "The Johnson-Holmquist Ceramic Model as used in LSDYNA2D," 1998.

[10] Q. Wang, Z. Chen, and Z. Chen, "Design and characteristics of hybrid composite armor subjected to projectile impact," Materials \& Design, vol. 46, pp. 634-639, 2013. 